ARTÍ́CULOS ORIGINALES Rev Chil Salud Pública 2016 Vol 20 (1): 29-35

\section{PERCEPCIÓN CULTURAL RESPECTO AL EMBARAZO NO PLANEADO DE MUJERES GESTANTES VIVIENDO CON VIH ${ }^{i}$ Cultural PERCEPTION ABOUt UNPLANNED PREGNANCY OF PREGNANT WOMEN LIVING WITH HIV}

\section{RESUMEN}

Objetivo: En el presente trabajo se exploraron percepciones culturales de mujeres gestantes viviendo con VIH que cursaron un embarazo no planeado, con la finalidad de comprender su toma de decisiones en lo relativo a la vida reproductiva.

Material y métodos: Todas las mujeres fueron atendidas en el Instituto Nacional de Perinatología, México. El estudio tuvo un enfoque sociocultural con una base metodológica cualitativa, y se realizó análisis del discurso. Previo consentimiento informado, a cada mujer se le aplicó una entrevista semiestructurada. Se estudiaron 15 gestantes con VIH que no planearon su embarazo. Los temas principales que se exploraron en la entrevista fueron: 1) significado del embarazo; 2) percepción de la infección por el VIH;3) motivos para continuar el embarazo no planeado; y 4) preocupaciones de la tríada mujer-maternidad-VIH.

Resultados: La razón más frecuente para continuar el embarazo no planeado fue la percepción sociocultural del aborto como crimen. Los familiares $y$ el personal de salud fueron las personas que con mayor frecuencia sugirieron continuar el embarazo.

Conclusiones: El contexto social y cultural que determina las creencias y significados sobre la infección por el VIH y la reproducción, tiene un papel fundamental para comprender el comportamiento de las embarazadas gestantes viviendo con VIH. A estas mujeres se les debe proporcionar la atención sin prejuicios y sugerirles las opciones de manejo solicitándoles su opinión.

Palabras clave: Virus Inmunodeficiencia Humana, mujer gestante, embarazo no planeado, percepción sociocultural, aborto.

(i) Trabajo recibido 11 de junio 2015; aceptado para su publicación 9 de diciembre 2015. 


\section{ABSTRACT}

Objective: The objective of this study was to explore the sociocultural view of unplanned pregnancy of women living with the human immunodeficiency virus (HIV), who were patients of the National Institute of Perinatology, México City, intending to understand the decisions concerning their reproductive lives. The study had a sociocultural qualitative approach.

Material and Methods: Each woman included in the investigation underwent a semi-structured interview; all provided informed consent. We studied 15 pregnant women living with HIV. The main topics explored in the interview were: 1) meaning of pregnancy; 2) perception of the $H I V$ infection concept; 3) cultural reasons for continuing with unplanned pregnancy, and 4) concerns about maternity and living with HIV.

Results: The most frequent responses to the question: why continue the unplanned pregnan$c y$ ? were, firstly, the perception in their social sphere that abortion is a crime, and secondly, the suggestion of relatives and health workers to continue the pregnancy.

Conclusions: We conclude that the social and cultural context that determines the beliefs and meanings of HIV infection, and of reproduction have an important role in understanding the behavior of $H I V$-infected pregnant women. These women must be given unprejudiced medical attention, discussing with them different management options.

Keywords: Human Immunodeficiency Virus, pregnant women, unplanned pregnancy, sociocultural perception, abortion.

\section{INTRODUCCIÓN}

La infección por el Virus de Inmunodeficiencia Humana (VIH) es un problema de salud pública a nivel global, que por su amplia distribución en el mundo constituye una pandemia con un alto impacto en la morbilidad y mortalidad de los habitantes de muchos países. ${ }^{1}$

En el reporte de la respuesta global al VIH/ SIDA del año 2011, ${ }^{2}$ la Organización Mundial de la Salud (OMS) y el programa de las $\mathrm{Na}$ ciones Unidas contra el SIDA (ONUSIDA/ UNAIDS), señalaron que en la región de Latinoamérica el $36 \%$ de las personas que adquirieron VIH son mujeres, con prevalencia entre aquellas de 15 a 24 años del 0-2\%.

Se considera que en países de recursos limitados, las mujeres presentan una vulnerabilidad mayor a la infección por el VIH, debido entre otros factores a un menor acceso a la educación, información y a servicios adecuados de salud. ${ }^{3}$ A pesar de los señalamientos de Naciones Unidas sobre la mejoría en las condiciones de igualdad de género y el empoderamiento de las mujeres, de acuerdo con las metas del Milenio 2015, ${ }^{4}$ la disparidad de género sigue siendo amplia, principalmente en países pobres. ${ }^{4}$

Se sabe que las causas de la pandemia por el VIH es multifactorial: existen factores biológicos, sociales, económicos, políticos y culturales. En la actualidad las personas ya no mueren por el virus VIH cuando reciben un tratamiento adecuado, es decir, la presencia de VIH se percibe como cualquier enfermedad crónica -cáncer, hepatitis $\mathrm{C}$, diabetes, hipertensión-. Mientras exista un control adecuado, las personas pueden decidir sobre su vida familiar, económica, sexual y reproductiva.

Lo cierto es que la discriminación o rechazo de la población hacia las personas con diagnóstico VIH, las coloca en un escenario de vulnerabilidad que puede afectar su salud..$^{4-7}$

Asimismo, se habla de la inequidad de género como uno de los factores más importantes que favorece el contagio en las mujeres ${ }^{3,8-10}$ debido a que limita su capacidad para tomar decisiones respecto a su cuerpo, sexualidad y reproducción. La disminución en estas capacidades conduce a un escenario de mayor vulne- 
rabilidad ante las infecciones de transmisión sexual, incluido el VIH. ${ }^{11-15}$ En ese sentido, el evento del embarazo y su relación con la presencia de VIH determinan una condición particular en la salud de la mujer gestante.

En el presente trabajo se reflexiona acerca de algunas percepciones socioculturales de las mujeres embarazadas con VIH que no planearon su embarazo, enfocadas específicamente al significado del embarazo, decisión de continuar la gestación, percepción respecto a ser mujer y la maternidad en el contexto de estar infectada por el VIH.

\section{MATERIAL Y MÉTODO}

El estudio incluyó mujeres embarazadas con $\mathrm{VIH}$, atendidas en el Instituto Nacional de Perinatología (INPER) de la Ciudad de México, institución de salud especializada en la atención de mujeres con embarazos de alto riesgo.

El estudio tuvo un enfoque sociocultural con base metodológica cualitativa, ${ }^{16}$ mediante la cual se pudieron identificar razones y significados sobre la condición de salud y estado reproductivo. El tipo de muestreo fue por conveniencia y el grupo total de informantes, de 17 mujeres embarazadas con VIH; de las cuales se seleccionó a 15, quienes manifestaron no haber planeado su embarazo. Los criterios de selección de las informantes fueron: mujeres embarazadas con VIH, quienes no planearon el embarazo, determinando un perfil entre ellas; el criterio de saturación se determinó al obtener elementos básicos de la información. ${ }^{17}$ Ésta se obtuvo de marzo a junio de 2011 a través de entrevistas semiestructuradas, las cuales fueron audiograbadas; también se realizaron notas de campo.

Los temas principales que se exploraron en la entrevista fueron: 1) algunas razones de la decisión de continuar el embarazo no planeado, 2) significado del embarazo, y 3 ) percepción respecto a ser mujer, la maternidad y el VIH. Además se aplicaron cuestionarios que indagaban sobre la historia reproductiva de las participantes, características sociodemográficas y situación económica. Las candidatas firmaron carta de consentimiento informado, en la que se exponen los criterios de confidencialidad y manejo de la información, respetando su anonimato por medio de seudónimos.

Se usó el análisis del discurso para la discusión de la información objeto de estudio. Para ello, en primer lugar se crearon códigos operacionales dándole definición a cada uno; posteriormente se codificaron cada una de las entrevistas por temas; la organización de las mismas se realizó con el apoyo del paquete de análisis cualitativo Atlas ti V5. ${ }^{18}$

\section{RESULTADOS}

\section{Escenario de las mujeres embarazadas con VIH}

El promedio de edad de las mujeres estudiadas fue de $30+/-8.3$ años, una de ellas tenía 16 años, seis se encontraban entre los 24 y los 30 años de edad y siete entre los 31 y 37 años. Siete vivían en unión libre y la mayoría de ellas, 14, señalaron profesar la religión católica. El promedio del conjunto de informantes del nivel escolar fue de secundaria, y más de la mitad (10/15) se dedican a labores del hogar.

En términos reproductivos, la mayoría (12/15) tenía hijos vivos previos al embarazo actual, dos de ellas tuvieron el antecedente de al menos un hijo infectado por el VIH, cuya vía de trasmisión fue la perinatal.

En su mayoría (14/15) manifestaron haber usado algún método de anticoncepción, siendo el preservativo el más empleado. De las 15 mujeres embarazadas, cinco mencionaron haber pensado en interrumpir su embarazo.

En seis casos, se identificó la presencia de parejas discordantes, es decir, de estas mujeres sus parejas varones no estaban infectadas de VIH. En todos estos casos, el hombre conocía el estado de infección de su pareja antes de que ésta se embarazara.

\section{Percepciones culturales de las mujeres ges- tantes con VIH}

Las reflexiones siguientes tienen como base la crítica a la imposición sociocultural de género 
en la sociedad occidental hacia las mujeres, enfocado a la importancia que se le atribuye al rol de madre y al ejercicio de la maternidad. Es decir, cómo dicha demanda cultural 'obliga' a las mujeres a tener que tomar decisiones que están fuera de sus proyectos de vida; por ejemplo, en el caso de las mujeres con VIH quienes tienen un embarazo no planeado.

Dentro del contexto de los significados del embarazo, se encuentran los motivos del embarazo y los argumentos que las mujeres mencionaron cuando se les preguntó acerca del porqué se habían embarazado. Las respuestas más significativas de las pacientes fueron las siguientes:

Una de las explicaciones está relaciona$\mathrm{da}$ con la poca información que ellas tienen respecto a la enfermedad orientada a la baja incidencia que en la actualidad existe de transmisión vertical cuando se lleva un tratamiento adecuado durante el embarazo. ${ }^{19}$

En su mayoría las mujeres del estudio señalaron que usaban el preservativo sin la combinación de otro método anticonceptivo, hecho que refleja el reciente debilitamiento de las campañas públicas de control de la natalidad. Lo anterior se relaciona también con la disminución en el uso sistemático de métodos más seguros, condición que se puede extrapolar a todas las realidades circundantes de las mujeres, independientemente de si viven o no con VIH.

También resalta entre las explicaciones que las mujeres nos brindan, lo relativo a la percepción del concepto de enfermedad, es decir, ellas "no se sentían enfermas", por lo que no se preguntaban acerca de la posibilidad de reproducirse. La percepción de enfermedad involucra también la esfera reproductiva, en vista de que aquella se entiende como un ciclo de malestares-tratamientos-debilidad y muerte. La condición de vivir con VIH no es conceptualizada como enfermedad sino como un discurso médico inconexo con la vida cotidiana. Lo anterior está relacionado con el contenido sociocultural del concepto de enfermedad, partiendo del pensamiento médico que naturalmente asocia a una persona enferma con aquella que presenta síntomas visibles como palidez, fiebre, debilidad, esca- lofríos. Pero si hablamos solo de la presencia del virus, en un examen clínico, sin manifestaciones explícitas de enfermedad, las personas tienden a pensar que no están enfermas, y el concepto del VIH se convierte en algo ajeno a sus vidas.

Este conjunto de argumentos derivados del significado de su estado de salud y reproductivo, se puede resumir en la siguiente narrativa:

El embarazo no fue planeado y al principio si me dio mucho miedo, pensé en abortar; pero después los dos fuimos con el doctor $y$ ya nos explicó, me dijo "mientras tú estés con tu tratamiento...". Entonces le vamos a echar ganas para que todo salga bien; yo me siento bien, siento que no tengo el VIH (Elvira, 27 años).

Dentro de los significados del embarazo para las mujeres viviendo con VIH, se estudiaron también aquellos motivos culturales que derivaron en continuar con el embarazo, a pesar de no haber sido programado. Cuando se les preguntó acerca de la interrupción temprana de la gestación, una tercera parte comentó que pensaron en ello, pero en realidad ninguna lo llevó a cabo. Exploramos también las razones por las cuales decidieron continuar con el embarazo. Es interesante que la convicción religiosa fue una de las razones principales para llevar a término su embarazo. Uno de los argumentos más comunes fue que la existencia del embarazo era obra de Dios. El destino fue otra razón: "nadie le pidió venir al bebé, es decir, concurrió resultado del azar”.

En la decisión de continuar el embarazo influyó también el entorno social y familiar: a) La culpa fue una de las principales razones. Al pensar en interrumpir su embarazo, ellas sentían que estaban cometiendo un acto de egoísmo, las llevaba a pensar en la autoconsideración. b) La percepción sociocultural respecto al acto del aborto. Esta situación se presentó en dos dimensiones: una enfocada a la relación entre el acto del aborto y el asesinato, esto es, la estigmatización del aborto como crimen (delito) que per se conlleva peso moral, jurídico y emocional para 
las mujeres; y una segunda, consistente en la exigencia de la familia y el personal de salud de continuar el embarazo rechazando la opción de interrumpirlo; a pesar de que desde el año 2007 en la Ciudad de México es legal el aborto antes de la duodécima semana de gestación. ${ }^{20}$ Veamos una narrativa que permite comprender parte de lo dicho por este grupo de mujeres:

Me citaron el 23 de enero para terminar mi embarazo. Mi hermana me dijo que "cómo era posible que yo fuera a interrumpir mi embarazo, si era un asesinato lo que yo estaba haciendo" (Rosaura, 25 años).

Pasando al dilema respecto a si continuar o no con el embarazo, las mujeres durante esta etapa vivieron una serie de preocupaciones trastocadas por la tríada mujer-maternidad-VIH. Las principales preocupaciones que señalaron fueron:

1. El tiempo de vida que les queda para compartir y cuidar a sus hijos, así como el tipo de cuidado y cuidadores que tendrán en su ausencia.

2. La preocupación económica aumentó en aquellas con descendencia.

3. La falta de información respecto a las precauciones existentes para evitar la transmisión vertical provocó intranquilidad al saberse embarazadas.

Ya son tres hijos, le damos gracias a Dios que están sanos, las dos ya están dadas de alta, y ahora con el bebé vamos a ver cómo nos va en el estudio, por esa parte no quisiera tener más hijos. Además, sentí mucha presión porque son muchos gastos, es empezar de cero (Juana, 24 años).

La presencia de un hijo las hace sentir mujeres socialmente aceptadas por el hecho de poder procrear, separando la condición de salud-enfermedad.

Muchas cosas; en primer lugar, pues, es que me hace sentir una persona igual como todas, porque a veces yo llegaba a decir "no, pues, ya no soy... ya no valgo, ¿no?, como los que valen al cien". Y abora que veo al bebé, pues, soy igual que todas las mujeres, soy igual, simplemente con el problema, pero eso no quiere decir que deje de ser mujer, entonces... eso (Daniela, 31 años).

Es interesante que a este grupo de mujeres la decisión de procrear, les da otra significación del ser mujer, no se sienten limitadas por su condición de salud en el ejercicio de la maternidad, aunque lo vivan con miedo. Podríamos decir que es una manera de no autodiscriminarse, y de aceptar su derecho a decidir en la procreación como cualquier mujer con o sin el virus.

\section{DISCUSIÓN}

El ONUSIDA estimó que a finales de 2011,21 el número de personas de 15 o más años, que adquirió la infección por VIH en el mundo fue de 2.2 millones. México muestra desde hace ya algunos años, una tendencia favorable en la baja del número de nuevos casos perinatales; sin embargo, aún se dan aunque en menor medida nacimientos de recién nacidos que adquirieron $\mathrm{VIH} .^{22}$

Es interesante comentar que para el caso de las mujeres gestantes viviendo con VIH, no se reportan cifras -al menos a nivel nacional- que permitan conocer cuántas mujeres gestantes adquirieron el VIH/SIDA. De hecho en la Asamblea General de las Naciones Unidas sobre VIH/SIDA del año de 2008, México, a través de la Secretaría de Salud, reconoció dicha carencia. Si consideramos la ausencia de cifras en este grupo de población, y lo reflexionamos desde la perspectiva de la salud pública, lo anterior representa un problema serio, ya que implica no tener un control real del problema. Por una parte, las mujeres que no conocen su estado de salud, suelen tener menos posibilidades de limitar la progresión de la enfermedad, lo que las lleva a deteriorarse de manera más rápida; y por otra parte, al ignorar su condición durante la gestación, evidentemente no efectuarán medidas preventivas de transmisión vertical. 


\section{La importancia de la mirada sociocultural en mujeres embarazadas viviendo con VIH}

Se sabe que las personas somos seres relacionales, y parte de nuestras decisiones están permeadas por condiciones individuales, socioculturales y de género. Respecto al evento reproductivo identificamos que en las mujeres embarazadas con VIH las condiciones socioculturales de su espacio inmediato son determinantes. Al ocurrir un embarazo no planeado se presenta para la mujer una serie de interrogantes, por ejemplo pensar en la posibilidad de interrupción del embarazo que las lleva a experimentar un conjunto de sentimientos, como la culpa por el contenido sociocultural que se le atribuye a la palabra aborto. Lo que contrapone su accionar con su deseo, es decir, si bien varias de ellas sí pensaron en interrumpir su embarazo, una serie de argumentos sociales se lo impidieron. En este hecho se observa el poco poder de decisión que las mujeres tienen respecto a su reproducción y su cuerpo..$^{8-10}$

El limitado poder de decisiones trastoca el cuidado de su salud en general, al determinar el tipo de medidas preventivas, por ejemplo realizarse o no una prueba de escrutinio sobre la infección por el VIH, acudir a los servicios médicos o llevar a cabo su tratamiento antirretroviral; asimismo con el cuidado de su salud reproductiva: decidir embarazarse, continuar o no con su embarazo no planeado o elegir un método de anticoncepción.

\section{El ámbito de los servicios de salud}

Comúnmente cuando una mujer embarazada llega a consulta y previamente ha sido atendida por la presencia del VIH, el personal de salud suele juzgarla por su decisión del embarazo, colocándola como culpable de la situación, y bajo esa premisa se da la atención por parte del personal. Lo anterior se debe a que las afectadas con frecuencia no son percibidas por quienes las atienden como personas inte- grantes de familias socialmente constituidas; si bien hay una responsabilidad individual respecto al comportamiento en los diferentes espacios sociales, es cierto que las decisiones, como en el caso de la reproducción, no son exclusivamente personales, sino que el contexto sociocultural es determinante en el actuar, como sería responder al contenido del rol de género socialmente impuesto.

Si la misión del personal de salud es una atención respetuosa y con principios éticos para garantizar la integridad de las mujeres embarazadas con VIH, es necesario que el sistema de salud considere las razones socioculturales de las mujeres respecto a continuar o interrumpir su embarazo. Es un derecho reproductivo que la mujer decida sin ser juzgada, dándole opciones de asistencia médica: la atención obstétrica o la interrupción legal del embarazo; sobre todo que esta última es legal en la Ciudad de México desde el año 2007.20

Tener escasa información acerca de la prevención en la transmisión vertical del virus (madre-hijo), limita a las mujeres del estudio en los argumentos para decidir continuar o interrumpir un embarazo no planeado. Del mismo modo, que hayan señalado exclusivamente el uso del preservativo, refleja la falta de conocimiento de métodos más seguros. En ese sentido, es urgente realizar campañas públicas de control de la natalidad que garanticen el uso sistemático de métodos anticonceptivos en los centros de atención de cualquier nivel. Estar informadas permitiría a las mujeres tomar decisiones de acuerdo a sus necesidades.

Es importante entonces señalar que la atención en las embarazadas viviendo con VIH debe ser multidisciplinaria, considerando los aspectos sociales, familiares, económicos, psicológicos y culturales, aunados a la clínica; ya que así construyen su propia condición de salud - enfermedad, y con base a ella toman decisiones sobre su reproducción y cuidados. 


\section{REFERENCIAS}

1. Álvarez-Gayou JL, Bravo García E, Bronfman M, et al. SIDA: Aspectos de Salud Pública. Manual. México. Informe técnico NO: 970-721-340-X. México: Instituto Nacional de Salud Pública, CENSIDA, 2006.

2. World Health Organization, UNICEF, UNAIDS. Global HIV/AIDS response. Epidemic update and health sector progress towards Universal Access. Progress report, 2011; Geneva: WHO; 2011.

3. Herrera C, Campero L. La vulnerabilidad e invisibilidad de las mujeres ante el VIH/ SIDA: constantes y cambios en el tema. $S a-$ lud Pública Mex, 2002; 44: 554-64.

4. ONU. Objetivos de Desarrollo del Milenio Informe de 2015. Nueva York. Naciones Unidas, 2015.

5. Castro A, Farmer P. El estigma del SIDA y su evolución social: una visión desde Haití. Rev Antropología Social, 2005; 14: 125-44.

6. Infante C, Zarco A, Cuadra S. El estigma asociado al VIH/SIDA: el caso de los prestadores de servicios de salud en México. Salud Pública Méx, 2006; 48: 141-50.

7. Rodríguez E. Enfermedad y significación: estigma y monstruosidad VIH/SIDA. Rev Opción, 2006; 22:9-28.

8. Herrera C, Campero L. La vulnerabilidad e invisibilidad de las mujeres ante el VIH/ SIDA: constantes y cambios en el tema. $S a-$ lud Pública Mex, 2002; 44: 554-64.

9. García-Sánchez I. Diferencias de género en el VIH/sida. Gac Sanit, 2004; 18 (Supl 2): 47-54.

10. Garibi C. La compleja relación violencia de género-SIDA. Un acercamiento a la violencia institucional como factor de vulnerabilidad de las mujeres ante el VIH. Rev Latinoamericana, 2009; 3: 82-105.

11. Piccone S, Saraceno C. Genere: la costruzione sociale del femminile e del maschile. $2^{\mathrm{a}}$ ed. Bologna: Editorial ll Mulino, 1996.

12. Mabilla M. La perspectiva antropológica en la Difusión del VIH/SIDA en el África Subsahariana. En: Salud y Desarrollo: SIDA. Madrid: Medicusmundi, 2002; pp. 24-32.

13. Maciocco G. HIV/SIDA: crisis global Acción Global. En: Salud y Desarrollo: SIDA. Madrid: Medicusmundi, 2002; pp. 3-6.
14. Pedrosa L. Saberse infectadas. Repercusiones de la detección de VIH en mujeres diagnosticadas durante el embarazo. Desacatos, 2004; 6: 148-70.

15. Phaladze N, Tlou S. Gender and HIV/AIDS in Botswana: a focus on inequalities and discrimination. Gend Dev, 2006; 14(1): 23-35.

16. Taylor S, Bogdan R. Introducción a los métodos cualitativos de investigación. La búsqueda de significados. Barcelona: Paidós, 1997.

17. Guest G, Bunce A, Johnson L. How many interviews are enough: an experiment with data saturation and variability? Field Methods, 2006; 18:58-82.

18. Atlas ti v5: Qualitative Data Analysis [en línea] Scientific Software Development GmbH; c2002-2016 [consultado 10.12.2013]. Disponible en: http://www. atlasti.com/backwards.html

19. Mateo A, Marín R, Andino V et al. Prevención de la transmisión madre-hijo del VIH/ SIDA en países en vías de desarrollo. Rev Hosp M Gea Glz, 2002; 5: 59-74.

20. Grupo de Información en Reproducción Elegida. Los Derechos Reproductivos en la legislación y en las políticas públicas de México [en línea] México: GIRE; 2010 [consultado nov. 2013]. Disponible en: https:// www.gire.org.mx/publicaciones/hojas-informativas/derechoslegislacionpp_2010.pdf

21. ONUSIDA. Informe de ONUSIDA para el día mundial de SIDA 2011 [en línea]. [sin lugar]: Programa Conjunto de las Naciones Unidas sobre el VIH/SIDA; 2011 [consultado 20.02.2014]. Disponible en: http://www. unaids.org/sites/default/files/media_asset/ JC2216_WorldAIDSday_report_2011_es_0. pdf

22. CENSIDA (México). El VIH Sida en México [en línea]. México: Secretaría de Salud [consultado 8.01.2014]. Disponible en: http://www.censida.salud.gob.mx/.

23. Padilla P, Figueroa R, Plazola N. Factores relacionados con la falta de lectura de carteles que difunden prueba para detectar VIH en gestantes. Rev Cubana Salud Pública, 2014; 40: 31-8. 